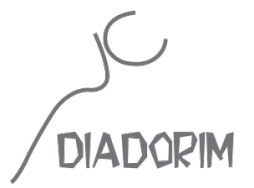

\title{
A GRAMÁTICA COMO DESCOBERTA ${ }^{1}$ GRAMMAR AS EXPERIMENTATION
}

\author{
Maria José Foltran ${ }^{2}$, Andrea Knöpfle ${ }^{3}$, Marcos Carreira ${ }^{4}$
}

\section{RESUMO:}

O objetivo deste trabalho é revisitar a discussão sobre ensino de gramática, feita nos últimos anos no Brasil, argumentando que esse ensino pode contribuir sobremaneira para maior compreensão da língua materna e de línguas estrangeiras, desde que embasado em conhecimento científico. Nosso encaminhamento é que o ensino de gramática precisa trabalhar com duas acepções: a) a gramática possibilita entender por que uma expressão linguística significa o que ela significa (Franchi, 1987); b) aprender gramática é aprender a explicitar regras que sabemos, mas que não são conscientes e, ao mesmo tempo, aprender a refletir sobre elas (a exemplo de Perini (1985), Larson (2010), Pilati et al. (2011), Costa et. al. (2011), Borges Neto (2012a; 2012b), Foltran (2013), Ferreira e Vicente (2015), Perini (2016), Bosque (2016), Pires de Oliveira e Quarezemin (2016), Vieira e Brandão (2016), inter alia.) Nossa contribuição, nesse quadro, é levantar novas apresentações que acreditamos serem fundamentais para o esclarecimento dessa concepção de ensino. Com a primeira acepção, argumentaremos contra a ideia de que a gramática não ajuda em nada na produção e compreensão de textos, tese amplamente defendida por alguns profissionais que defendem a aprendizagem da língua por meio de textos, apenas. Embora concordemos que o objetivo central do ensino de língua seja formar o cidadão, tendo por meta a leitura e compreensão de gêneros textuais, defendemos que a gramática tem um papel importante na aquisição desse conhecimento. Com a segunda acepção, demonstramos que o ensino de gramática é uma ferramenta única para explicitar um conhecimento interiorizado, permitindo um domínio maior em duas direções: a) desenvolver uma reflexão científica

\footnotetext{
1 A versão inicial deste trabalho foi apresentada X Congresso Internacional da ABRALIN em março de 2017 (UFF-Niterói, RJ). Agradecemos à audiência pelas sugestões. Agradecemos também aos pareceristas anônimos pelas sugestões que ajudaram a aprimorar este texto. As inadequações que restaram são de nossa inteira responsabilidade. 2 Doutora em Linguística pela Universidade de São Paulo (USP), Professora Titular da Universidade Federal do Paraná (UFPR), Pesquisadora do CNPq (processo 304767/2016-6).

3 Doutora em Letras (estudos linguísticos) pela UFPR e Professora Adjunta da Universidade Federal de Pernambuco (UFPE).

4 Doutor em Letras (estudos linguísticos) pela UFPR e Professor Adjunto da Universidade Estadual de Ponta Grossa (UEPG).
} 
sobre um fato natural, a linguagem, por meio de uma metodologia que pode ser generalizada para qualquer outro campo científico; b) perceber o funcionamento das línguas naturais. Nessas bases, o ensino de gramática não pode mais ser entendido como ensino da modalidade culta (nos termos de Faraco, 2008), embora ninguém negue que possibilitar o domínio da vertente culta da linguagem seja atribuição da escola. Concluímos o trabalho mostrando a necessidade de separar ensino de gramática e ensino de língua culta. Somente assim o ensino de ambas pode fazer sentido e produzir resultados positivos.

PALAVRAS-CHAVE: Ensino de gramática; Regras gramaticais; Ciência.

\section{ABSTRACT:}

The goal of this work is to revisit the past years discussion that has been made in Brazil about the teaching of grammar, arguing that this teaching can especially contribute to a better native (as well as foreign) language understanding, to the extent that it is based on scientific knowledge. We hereby stand for a grammar teaching work supported by two concepts: a) grammar enables to understand why a linguistic expression means what it means (Franchi, 1987); b) learning grammar is to learn how to make explicit rules already known (yet unconsciously) by the speaker, and also to learn to reflect on these rules (along with Perini (1985), Larson (2010), Pilati et al. (2011), Costa et. al. (2011), Borges Neto (2012a; 2012b), Foltran (2013), Ferreira e Vicente (2015), Perini (2016), Bosque (2016), Pires de Oliveira e Quarezemin (2016), Vieira e Brandão (2016), inter alia.). Within this context, our contribution is to raise some new conceptual and working approaches which we believe to be crucial to clarify the alleged learning-teaching conception. Along with the first concept, we argue against the idea that the grammar does not help at all with text reading and writing - a thesis widely defended by some professionals who support the language learning by means of texts only. Although we agree that the central aim of language learning is to contribute to the citizenship formation, in which the reading and comprehension of text genre is the goal, we defend that grammar has an important role in the acquisition of this knowledge. As for the second concept, we demonstrate that the teaching of grammar is a tool to make an internal knowledge explicit, allowing a broader understanding domain in two directions: a) to develop a scientific reflection on a natural fact, the language, via a methodology that can be generalized to any other scientific field; b) to acknowledge the natural languages mechanisms. On these grounds, the teaching of grammar can no longer be understood as the teaching of the standard language (as in Faraco, 2008), although no one denies the school's assignment in enabling the mastery of the standard variety. We conclude this work by showing the necessity to drive apart the teaching of grammar from the learning of the standard language. Only this way both works can make sense and produce positive results.

KEYWORDS: Teaching of grammar; Grammar rules; Science.

\section{Introdução}

A partir de meados do século passado, a discussão sobre o ensino de língua materna sai de uma seara estritamente didático-pedagógica e entra para o domínio da linguística, ciência que vivia um momento bastante fértil com o desenvolvimento, em especial, das pesquisas estruturalistas 
e dos estudos sociolinguísticos. A discussão sobre o ensino de línguas que, até então, era capitaneado por profissionais da educação, passa a ser de interesse dos linguistas ${ }^{5}$ que, embasados nas abordagens mais recentes da área, entendem que podem dar contribuições mais avalizadas para o debate.

Essa discussão foi desencadeada pela percepção de que o ensino de língua materna ia muito mal. As diferentes análises que foram feitas eram unânimes em apontar um problema: os egressos do sistema apresentavam sérias dificuldades de leitura e de escrita (Pécora, 1983; Back,1987). Diante desse diagnóstico, houve grande adesão à solução proposta para se contornar essa deficiência: era necessário alterar o foco de ensino da gramática para o ensino de texto (leitura e escrita) (Geraldi, 1985) ${ }^{6}$. Tínhamos, portanto, identificado um problema e havia uma solução que se entendia como redentora. A consequência imediata desse quadro foi a condenação da gramática, que passa a ser vista como a grande vilã do processo. Antes de passarmos para a discussão central deste artigo, o ensino de gramática, precisamos entender nuances desse quadro que gerou tais avaliações.

Nos anos 1940, o sistema escolar brasileiro vinha passando por reformas lideradas pelo ministro Gustavo Capanema, objetivando o que se chamou de democratização de acesso. Lembremos que, antes disso, não havia nenhuma garantia de vaga para todo e qualquer cidadão. Apenas crianças e jovens das classes mais abastadas logravam êxito nessa disputa, principalmente na possibilidade de permanecer nas séries mais adiantadas ${ }^{7}$. Nos anos 1970, o projeto de universalização do ensino se traduziu por uma verdadeira explosão, ampla e rápida, da rede escolar. Isso permitiu que uma nova clientela, até então preterida, tivesse acesso ao sistema de ensino - uma clientela que trouxe consigo variedades linguísticas estigmatizadas, com as quais a escola não estava habituada: as camadas populares que adentram no sistema escolar nesse momento dominam outras normas, "incultas" em contraposição ao padrão dominante ${ }^{8}$. Além disso, para atender ao grande fluxo de estudantes, o sistema precisou também aumentar significativamente o número de professores. Desse modo, profissionais sem formação adequada - dependendo do lugar, sem habilitação alguma - passaram a conduzir o importante e difícil processo de aprendizagem. Para piorar, houve uma degradação digna de nota nos salários pagos a esses profissionais, acarretando perda não só financeira, mas de prestígio social. Não era o ensino de português que ia mal, mas era todo o sistema escolar que entrava em colapso (Mercer e Foltran, 1992-93). Isso não significa assumir que o problema foi a democratização da escola, mas significa mostrar que ela foi feita sobre pilares improvisados, que nem tudo deu certo'.

Nesse contexto, como já foi observado, o ensino de gramática passa a ser altamente questionado. A crítica, em boa parte adequada, era que se ensinava nomenclatura gramatical ao invés de língua. A partir daí, assume-se que as habilidades de ler e escrever independiam do ensino de

\footnotetext{
Já em 1970, na introdução do livro "Estrutura da Língua Portuguesa", Câmara Jr. se manifesta a respeito desse tema.

Este livro, de organização de João Walderley Geraldi, reúne diferentes autores que fazem um balanço do ensino de português. Alguns se detêm em criticar a prática adotada, outros explicitam os novos conceitos de linguística que deveriam respaldar o ensino e, outros, ainda, sugerem novas práticas pautadas na leitura e na escrita.

7 Maiores detalhes sobre esse período em Mercer e Foltran (1993).

8 É importante observar que, ainda nos dias de hoje, a escola tem dificuldades em lidar com essas variedades estigmatizadas.

9 Não é objetivo deste artigo apresentar as diferentes reformas por que passou o ensino brasileiro a partir da década de 1930. Regina Zilberman faz uma excelente sinopse desse quadro na apresentação do livro "Metodologia e Prática de Ensino de Língua Portuguesa" de Travaglia et al. (1984).
} 
gramática: aprende-se a ler, lendo e aprende-se a escrever, escrevendo. Para isso, o instrumental que se mostrava mais plausível a esses objetivos era o da linguística textual: coesão, coerência e gêneros textuais. Vale citar alguns equívocos nos rumos tomados. O primeiro deles é que a noção de gramática que sempre prevaleceu na escola é a da gramática normativa: conjunto de regras da 'boa linguagem' ${ }^{\prime 10}$. Outro equívoco é partir para posições dicotômicas: ou se ensina isso ou aquilo. A análise linguística pode abarcar diferentes esferas e campos do conhecimento. Precisamos ampliar o leque e não limitá-lo, levando em consideração, inclusive, que o ensino baseado na linguística textual pode cair no mesmo erro, ou seja, ensinar nomenclatura.

Faraco (2008), analisando o contexto apresentado acima, observa que ensinar gramática passou a ser "politicamente incorreto" (p.23). A solução para enfrentar essa depreciação, levando-se em conta que o ensino não sofrera mudanças substanciais, foi encontrar um novo termo. $\mathrm{O}$ termo cunhado para isso foi norma culta $^{11}$. A nova expressão dava um ar de modernização para as antigas práticas, que continuavam (continuam?) em exercício. Diga-se de passagem que esses fatos, como observa Faraco, se deram com base, principalmente, em duas manifestações que vinham da área da Linguística: (i) baseados nos estudos estruturalistas, os acadêmicos apontavam as fragilidades conceituais da gramática tradicional, contribuindo assim para seu desprestígio; (ii) com a difusão das teorias de variação linguística, apontava-se para a necessidade de não se discriminar as variedades não-prestigiadas, dando origem à interpretação equivocada de que o domínio da norma culta podia deixar de ser objeto de ensino. Esses equívocos foram nefastos para o ensino de língua materna e acarretaram um mascaramento da situação. Neste trabalho, vamos enfatizar novas coordenadas sobre o ensino de gramática. Importante esclarecer que os encaminhamentos assumidos aqui não são inéditos. O posicionamento defendido já foi explorado por diferentes linguistas no Brasil e fora dele, como em Perini (1985), Larson (2010), Pilati et al. (2011), Costa et. al. (2011), Borges Neto (2012a; 2012b), Foltran (2013), Ferreira e Vicente (2015), Perini (2016), Bosque (2016), Pires de Oliveira e Quarezemin (2016), Vieira e Brandão (2016), inter alia. Achamos, no entanto, que novas apresentações são fundamentais para o esclarecimento dessa concepção de ensino e acreditamos ser essa nossa contribuição. Para uma implementação eficaz dessas orientações, é necessário, antes de tudo, ter uma noção clara do que seja norma culta. Remetemos o leitor a Faraco (2008), para maior compreensão a respeito da complexidade que há em torno de se conceituar norma culta.

Faz-se necessário, portanto, um reposicionamento do ensino de gramática na Educação Básica. Para tanto, precisamos entender as implicações do termo 'gramática'. Ao invés de encararmos a gramática como lei, precisamos entendê-la como método científico que nos faculta a compreensão de como uma língua funciona, tendo como objeto central a língua portuguesa. Vamos

\footnotetext{
10 Vamos detalhar as noções de gramática na seção seguinte.

11 Faraco faz um excelente balanço do momento em que a gramática tradicional é colocada em xeque. A partir da década de 1960, com a difusão no Brasil dos estudos estruturalistas, a crítica acadêmica aponta inconsistências conceituais e empíricas na gramática tradicional. A partir do desprestígio da velha gramática, cunha-se o termo 'norma-culta', que é utilizado algumas vezes em alternância à expressão "norma-padrão", como se fossem o mesmo fenômeno. Outras vezes o termo é usado para designar a norma estipulada em gramáticas e dicionários (norma gramatical). E, segundo o autor, o termo foi usado também para maquiar a depreciação semântica do termo gramática, buscando-se um nome novo para a velha prática, ou seja, a centralidade do ensino de gramática nas aulas de português.
} 
defender aqui que fazer gramática significa explicitar um conhecimento que já dominamos inconscientemente. Para isso, assumimos que o falante tem um conhecimento implícito ${ }^{12}$, que vai servir de ponto de partida para qualquer atividade. Neste artigo, vamos privilegiar questões sintáticas em nossa discussão.

A sintaxe é uma parte da gramática que lida com a estruturação de palavras e sintagmas em sentenças. Uma análise sintática adequada deve revelar acima de tudo por que uma sentença significa o que ela significa (Franchi, 1987) e deve explicitar por que temos determinadas possibilidades de arranjos e não outras.

Este artigo seguirá os seguintes passos: na seção 1, vamos revisitar os conceitos de gramática e apresentar a gramática como método científico; na seção 2, discorreremos sobre algumas regras sintáticas que possibilitam uma visão mais clara da estrutura sintática, bem como lançamos encaminhamentos para um ensino nessas bases; e, na seção 3, apresentaremos nossas considerações finais.

\section{Sobre gramática}

A tradição gramatical ocidental foi construída sobre pilares que são hoje colocados em xeque. Os alexandrinos, no séc. III a.C, se empenharam, por meio de pesquisas literárias e linguísticas, em recuperar manuscritos antigos, em especial os poemas homéricos, que se encontravam bastante corrompidos. Esses filólogos buscavam restaurar o texto original. Observaram que a língua dos textos clássicos diferia em muitos aspectos do grego contemporâneo da Alexandria. A partir dessa constatação, adotaram a prática de publicar comentários de textos e tratados de gramática para dirimir as dificuldades dos leitores. A grande admiração pelas obras literárias do passado encorajou a crença de que a língua, ou a variedade de língua na qual elas haviam sido escritas, era mais pura, mais correta do que a fala coloquial de então. As gramáticas helenistas, segundo Lyons (1979), tinham dupla finalidade: "combinavam a intenção de estabelecer e explicar a língua dos autores clássicos com o desejo de preservar o grego da corrupção por parte dos ignorantes iletrados" (p. 9). Essas crenças e procedimentos levaram ao que o autor rotulou de "erro clássico": falta de compreensão da maneira como a língua evolui e o entendimento equivocado de que a língua escrita precede a língua falada e não vice-versa. Se ao perceberem o descompasso da língua literária do passado com o grego falado do momento os filólogos concluíssem que o grego havia mudado, a história teria sido diferente. Ao contrário, os fatos observados os levaram a afirmar que o grego havia sido corrompido e era necessário restaurá-lo. É fácil depreendermos que as bases da gramática normativa tradicional estão calcadas nessa visão: há uma língua mais pura, melhor, utilizada por grandes escritores e qualquer desvio desse parâmetro constitui uma deturpação.

Os estudos linguísticos vieram desestabilizar esse quadro. Todas as manifestações linguísticas constituem fatos da língua. Uma expressão como 'língua portuguesa' é apenas um rótulo que abarca as mais diferentes variedades e todas essas variedades formam a língua. Algumas variedades têm maior prestígio social, mas isso é circunstancial, é apenas uma avaliação social, que pode e deve merecer atenção, pois uma pessoa letrada deve saber transitar por diferentes

12 Esse conhecimento pode ser entendido como competência, nos termos de Chomsky (1986). 
variedades. Na contramão dessa avaliação social, a linguística constata que todas as variedades são regidas por regras, ou seja, ninguém fala sem gramática. Simplesmente, há diferentes regras colocadas em uso. E isso servirá de base para as gramáticas descritivas: explicitar que regras regem o uso da língua nas diferentes variedades. Nesse sentido, a descrição se desprende das normas mais prestigiadas e volta-se, não só mas também, para as variedades sem prestígio. Como essa concepção vai contra o senso comum de 'língua correta', noção disseminada fortemente pela escola por meio da gramática normativa, é de se esperar a reação que se observa contra ela ${ }^{13}$. Constata-se facilmente que as pessoas não conseguem observar sua própria fala. As pessoas letradas, em especial, que deveriam ter condições para isso, já que passaram muito tempo nos bancos escolares, têm uma visão obscurecida pela rígida prescrição linguística que vivenciaram. É muito comum encontrar falantes letrados que afirmam categoricamente que não falam 'assim'. São necessários poucos minutos de observação mais acurada para fazê-los observar que, em momentos em que não estão se monitorando, usam formas linguísticas que eles próprios condenariam. E é exatamente isso que uma formação gramatical mais efetiva pode mudar: ensinar as pessoas a observar sua própria fala e constatar fatos linguísticos que divergem das formas prescritas. Essa conscientização da própria fala, da língua que nós usamos nos diferentes contextos, é que pode e deve ser desenvolvida com o ensino de gramática.

Para que essa empreitada seja bem sucedida, é imprescindível assumir que temos um conhecimento implícito da língua que falamos ${ }^{14}$. Isso significa dizer que as escolhas linguísticas que fazemos estão sempre de acordo com regras que estão internalizadas na nossa mente. Todo falante, sem exceção, opera com esse conhecimento. Tomar consciência dessas regras é um passo muito importante para que tenhamos mais controle sobre as escolhas que fazemos. Essa é a tarefa crucial no ensino de gramática: explicitar um conhecimento que já dominamos de forma inconsciente. Aprender gramática é aprender a reconhecer esse conhecimento implícito, ou seja, é tornar esse conhecimento consciente.

Muitos autores já explicitaram de forma bastante adequada essas diferentes concepções de gramática, rotulando-as como "gramática normativa", "gramática descritiva" e "gramática interna ou interiorizada". Para uma melhor sistematização desses conceitos, apresentamos a conceituação dada por Franchi (2006).

Em relação à gramática normativa, o autor esclarece:

Gramática [normativa] é o conjunto sistemático de normas para bem falar e escrever, estabelecidas pelos especialistas, com base no uso da língua consagrado pelos bons escritores.

Dizer que alguém "sabe gramática" significa dizer que esse alguém "conhece essas normas e as domina tanto nocionalmente quanto operacionalmente". (FRANCHI, 2006, p. 16)

Nessa concepção, um bom gramático seria aquele que diz como se deve escrever. Já a gramática descritiva é constituída de descrições estruturais e de regras que subjazem à língua. Nas palavras do autor,

13 Referimo-nos aqui especialmente às reações veiculadas pelos meios de comunicação.

14 Maiores detalhes em Costa et. al. (2011). 
Gramática [descritiva] é um sistema de noções mediante as quais se descrevem os fatos de uma língua, permitindo associar a cada expressão dessa língua uma descrição estrutural e estabelecer suas regras de uso, de modo a separar o que é gramatical do que não é gramatical.

Saber gramática significa, no caso, ser capaz de distinguir, nas expressões de uma língua, as categorias, as funções e as relações que entram em sua construção, descrevendo com elas sua estrutura interna e avaliando sua gramaticalidade. (FRANCHI, 2006, p. 22).

Franchi observa que, apesar de a gramática descritiva ser mais científica e neutra que a normativa, os fatos podem tomar outro rumo, pois o ponto de vista normativo pode introduzir-se sorrateiramente na gramática descritiva. Isso pode acontecer, primeiro, porque quem está descrevendo uma língua pode desconsiderar fatos coloquiais e populares, como se eles não existissem (no fundo, é o mesmo procedimento da gramática normativa). Segundo, porque o gramático pode reintroduzir critérios sociais de uso, excluindo como não gramaticais certos fatos linguísticos. $\mathrm{O}$ autor conclui que, embora a gramática descritiva não assuma os mesmos preceitos da gramática normativa, o que acontece habitualmente na prática escolar é que ela os incorpora, transformando-se em instrumento para prescrições de uso.

Outro viés é entender a linguagem como uma propriedade dos seres humanos, independentemente de fatores sociais, de raça, de cultura, de situação econômica, etc. Toda criança, tendo acesso à linguagem, domina rapidamente todo um sistema de princípios e regras que lhe permite ativar a gramática de sua língua. Franchi sistematizou essa acepção de gramática da seguinte maneira:

Gramática [internalizada] corresponde ao saber linguístico que o falante de uma língua desenvolve dentro de certos limites impostos pela sua própria dotação genética humana, em condições apropriadas de natureza social e antropológica.

"Saber gramática" não depende, pois, em princípio, da escolarização, ou de quaisquer processos de aprendizado sistemático, mas da ativação e amadurecimento progressivo (ou da construção progressiva), na própria atividade linguística, de hipóteses sobre o que seja a linguagem e de seus princípios de regras. (FRANCHI, 2006, p. 25).

Tendo esse quadro mais bem delineado, há que se observar que não existe uma 'gramática internalizada' na forma impressa ou configurada na forma de livro a ser consultado. Esse saber linguístico está disponível em todos os falantes da língua. Procedimentos metodológicos tornariam esse saber consciente para que se possa compreendê-lo e manipulá-lo. Nesse sentido, usamos no título a palavra 'descoberta'. É uma gramática que não se ensina, mas que pode ser vislumbrada à medida que refletimos sobre os usos linguísticos. Na próxima seção, vamos detalhar melhor esse procedimento. Antes disso, porém, gostaríamos de esclarecer de forma mais objetiva alguns pontos:

- Quando afirmamos que a escola deve ensinar gramática, estamos assumindo que essas diferentes acepções devem estar muito claras aos professores, para que eles possam tirar proveito de todo o conhecimento acumulado até os dias de hoje, conhecimento este propagado pelas gramáticas descritivas, mas também pelas gramáticas normativas. As boas gramáticas normativas incluem descrições apuradas que, contextualizadas, são de grande utilidade. Não estamos advogando, porém, um retorno à centralidade da gramática no ensino de língua. Ou seja, não afirmamos que a escola deva fazer só isso. Essa visão dicotômica de que ou se ensina isso ou aquilo 
é perversa. Além de gramática, deve-se trabalhar leitura e escrita, organização textual, oralidade, etc.

- Uma questão sempre cobrada quando essa concepção de ensino é abordada é se nossos professores teriam formação suficiente para assumir tal empreitada. Responder a uma pergunta como essa demanda uma reflexão sobre a formação de professores e isso foge aos propósitos deste artigo, apesar de suma importância. Reconhecemos que esta é uma questão a ser enfrentada. Os professores que dominam as dimensões que o termo 'gramática' abarca estão mais preparados para avaliar melhor os materiais produzidos para a escola que, não raro, são simplificações grosseiras de gramáticas normativas ${ }^{15}$.

- Portanto, quando defendemos uma nova postura no ensino de gramática, não estamos dizendo para jogar a gramática tradicional fora. Ao contrário, leituras eficientes de boas gramáticas tradicionais ajudam a tirar o ranço desse conhecimento ${ }^{16}$. Esse aprofundamento ajudaria a observar, também, que os gramáticos não são consensuais em muitas das prescrições que fazem, o que relativiza bastante a ideia de que há uma e só uma forma a ser usada.

\section{A gramática como metodologia científica}

A escola, em geral, trabalha com verdades absolutas. Dessa forma, passa a impressão de que os conceitos que ensina são inquestionáveis. Basta adentramos um pouco na filosofia da ciência para entendermos que um ingrediente fundamental do trabalho científico é a dúvida. Isso significa que devemos estar cientes de que qualquer resposta às questões apresentadas são hipóteses. Novas pesquisas podem levar a outras direções que nos obrigam a revisar conhecimentos já estabelecidos. Isso já aconteceu muitas vezes! Ao nos aprofundarmos na história da ciência, percebemos que os avanços foram sempre decorrentes da dúvida, dos questionamentos que se fizeram sobre verdades já assimiladas pelo senso comum.

De modo geral, a escola desconhece, não consegue explorar, a dúvida como uma forma de conhecimento. As questões são sempre apresentadas de maneira definitiva - descrições e leis como verdades absolutas - como se não coubesse nenhum questionamento. Os estudos sobre as lín-

\footnotetext{
15 Vale a pena recuperar algumas reflexões de Câmara Jr. (1970) a esse respeito. Ao expor os pressupostos da gramática normativa e da gramática descritiva, o autor levanta uma questão crucial: será que a gramática normativa deve ser abandonada? Argumenta que tal pergunta advém da confusão de duas disciplinas da linguística que são correlatas, porém independentes. Segundo ele, é preciso ter clareza que a gramática descritiva faz parte da linguística pura. Como toda ciência, a linguística teria um ramo normativo que poderia ser chamada de linguística aplicada, com a finalidade de regular um comportamento social. A escola seria o espaço onde essa aplicação se configuraria, pois o ensino precisa, necessariamente, estar assentado numa regulamentação. Acrescenta ainda que "o remédio é o professor de língua e os homens em geral aprenderem os princípios gerais da linguística. Para isso, a melhor solução parece ser fornecer-lhes uma gramática descritiva desinteressada de preocupações normativas.” (CÂMARA Jr., 1970, p. 16).

16 Faraco (2008) analisa crenças sobre formas linguísticas consideradas como as únicas 'certas' disseminadas pela imprensa, em especial, e as avalia à luz do que dizem bons gramáticos e filólogos. Constata que essas crenças são resultado de simplificações e de leituras inadequadas.
} 
guas humanas também percorreram esse caminho ${ }^{17}$. Apesar de termos provas incontestáveis de que as línguas mudam no tempo, são poucas as pessoas que conseguem olhar para as formas inovadoras como uma possível nova mudança. O mesmo acontece quando se fala em gramática. Rapidamente, os velhos manuais passam a ser citados sem que se procure entender como eles surgiram ou em que medida eles refletem a nossa realidade linguística.

Nosso ponto aqui é mostrar que o ensino de gramática é uma ótima oportunidade para uma formação científica inicial, para se despertar o espírito investigativo. Essa concepção foi e tem sido desenvolvida por diferentes linguistas, como já apontamos na introdução. Observar os fatos linguísticos que estão à nossa volta seria o ponto de partida e, baseados neles, estabelecer princípios e leis que regem diferentes usos da língua. Mesmo que não se consiga estabelecer regras conclusivas, a simples observação e descrição do que acontece já é uma maneira de tornar consciente esse uso. Se entendermos regras como conhecimento interno que estão disponíveis para orientar e organizar nossa fala, já é um passo eficiente para começarmos a desenvolver esse olhar sobre a língua. Um exemplo simples: é muito comum ouvirmos vou levá, vou comprá, vou vendê, vou dormi, quando a prescrição nos orienta a usar e escrever vou levar, vou comprar, vou vender, vou dormir. Isso é um fato e podemos tentar explicá-lo. É possível, a princípio, levantar uma hipótese: não pronunciamos o -r em final de palavras. Mas facilmente encontraríamos contraexemplos para tal generalização: ninguém diz má para mar, por exemplo, ou flô para flor $^{18}$. Portanto, a hipótese precisa ser reformulada: não pronunciamos o -r final de infinitivos. Comparar a pronúncia de verbos no infinitivo com substantivos terminados em -r passa a ser uma forma de aferirmos a regra que acabamos de enunciar e, para muitos, torna-se uma revelação e um desafio para a observação de novos fatos. Constatações simples como essa desmontam alegações de que falamos de tal jeito por descuido, por pressa, por ignorância. Vale observar que o apagamento do -r no final de formas infinitivas é realizado também por pessoas escolarizadas em momentos de baixo monitoramento. A observação de tais fatos, bem como sistematizar sua ocorrência por meio de regras e generalizações são forma de trazer à tona o conhecimento implícito que temos. Isso é fazer gramática e nesse sentido que afirmamos que essa atividade deve ser desvinculada do ensino de norma culta. Diante desses fatos, uma forma tradicional de ensino analisaria essas formas simplesmente com incorreções dos falantes. Na concepção que expomos aqui, a explicitação da regra que mostra que o apagamento do -r nas formas infinitivas é sistemático e pode ser explicado externaria a normalidade do fato. Ao explicar isso, o professor pode e deve chamar a atenção para a não correspondência entre língua falada e língua escrita (não falamos como escrevemos e não escrevemos como falamos). A necessidade de grafar o -r na escrita continua valendo.

O trabalho da ciência é entender e explicar os fatos com que nos defrontamos na realidade. Usar a língua como objeto de observação é uma tarefa mais simples, já que os dados a serem obser-

\footnotetext{
17 Isso se aplica também a outras ciências. O estudo das ciências em geral, no Brasil, prescinde de um método investigativo que fomente a dúvida e a curiosidade. A esse respeito, remetemos à leitura de Feynman (2000), sobre o ensino de física no Brasil. Trechos do livro podem ser acessados em (http://fisicadf.blogspot.com.br/2013/08/ ensino-de-fisica-no-brasil-segundo.html\#.WJhVafLzx6Y).

18 Algumas variedades do português podem apagar o -r em final de alguns substantivos. Portanto, a descrição desse fenômeno vai depender do grupo linguístico com que está se lidando. Por exemplo, podemos encontrar em determinadas variedades frô ou fulô.
} 
vados estão disponíveis a todos e são infindáveis. Construir regras gramaticais é tornar visíveis conhecimentos que já temos de maneira inconsciente, é tornar palpável algo que já sabemos, mas, em geral, não sabemos que sabemos. Desse modo, o aluno aprende a construir e aferir hipóteses, tendo como material bruto o seu próprio conhecimento ${ }^{19}$.

Importante salientar que essa tarefa pressupõe observar e descrever a língua como ela é. Isso pode levantar questionamentos: se o aluno se debruça sobre a língua que ele fala e com a qual convive nos diferentes espaços sociais, ele não vai aprender a norma culta? A princípio, a resposta é não. $\mathrm{O}$ objetivo primeiro não seria essa aprendizagem. Mas, com um trabalho nesses moldes, os estudantes não só entenderão o funcionamento da sua língua, da língua de sua comunidade, mas passarão também a observar melhor a língua usada nos textos lidos, a língua das redes sociais, da televisão, etc. Se eles tiverem uma orientação competente para essa observação e descrição, começarão a perceber as diferenças de fala nos diferentes extratos sociais, nos diferentes meios de comunicação, nos diferentes registros orais e escritos. É a partir desse confronto que será possível lidar melhor com as inúmeras avaliações sociais que se produzem a partir dos usos linguísticos: formas de muito prestígio, formas com pouco ou nenhum prestígio. Mas mais do que isso, não sairão dessa experiência com o pensamento equivocado de que não falam a sua língua. Ao contrário, perceberão que sabem mais do que imaginavam saber. E esse tipo de trabalho nos faz compreender exatamente isso: o que nós sabemos, mas não sabemos que sabemos. Quando assumimos isso, invertemos a crença disseminada pela escola que ninguém sabe falar a língua. No viés que propomos, chegaremos ao lado oposto: todos os falantes conhecem muito a língua que falam.

Nós sabemos (qualquer falante sabe) que um verbo como falar admite, como seu complemento, tanto um sintagma nominal (ele falou a verdade), como uma oração encaixada (ele falou que a Lia estava doente). E todos sabem, também, que um verbo como quebrar não admite uma oração encaixada como complemento ( $A$ Lia quebrou o vaso $X{ }^{\star} A$ Lia quebrou que estava sujo ${ }^{20}$ ). Sabemos, também, que um verbo como querer exige uma forma verbal no subjuntivo, quando há uma oração encaixada depois dele. Mesmo que o falante não conheça a nomenclatura "subjuntivo", sabe usar verbos nesse modo verbal, quando são requeridos (Meu pai quer que eu vá no encontro $X{ }^{*}$ Meu pai quer que eu vou no encontro $)^{21}$.

Como se pode ver, esse tipo de reflexão não parte de leis externas, mas não é incompatível com elas, já que permitirá contrapor o conhecimento implícito com as regras normativas, quando houver conflito. Portanto, nesse sentido, um trabalho assim dirigido não impede a apreensão de uma norma culta. Ao contrário, facilita. Além disso, alimenta o espírito investigativo, tão adormecido em nossas escolas. Como dizem Pires de Oliveira e Quarezemin (2016), "não há educação sem estudo, sem reflexão, sem curiosidade, sem perplexidade" (p. 19).

\footnotetext{
19 Pires de Oliveira e Quarezemin (2016) apresentam diversos fenômenos linguísticos para embasar reflexões desse tipo.

20 Como se costuma fazer nos trabalhos linguísticos, usamos o * antes de expressões ou sentenças que não ocorrem na língua. Trata-se de observar que a sentença ${ }^{*} A$ Lia quebrou que estava sujo é inaceitável no português, mas A Lia quebrou o que estava sujo é uma sentença da língua.

21 O uso do subjuntivo em estruturas como esta pode variar conforme o dialeto. Há dialetos que não fazem esse uso. Portanto, o aluno pode não ter esse conhecimento internalizado. É um conhecimento que precisará ser introduzido.
} 
Citando Perini (2016, p. 49), “a ciência não é um corpo de conhecimento e resultados; é o método de obter esses conhecimentos e resultados". Trabalhar com gramática enquanto ciência significa investigar como a língua se comporta em seus mais diferentes usos e como a língua se estrutura. A estruturação de uma sentença diz respeito à sintaxe. No encaminhamento que exploramos aqui, a análise sintática explora as possibilidades de estruturação de uma frase, no que diz respeito à formação e ordem de constituintes, à organização interna desses constituintes, à disposição das classes de palavras ou de categorias gramaticais, ao desencadeamento de concordância. Ressaltamos que o significado emerge a partir dessas relações. Desse modo, fazer uma análise sintática vai muito além de simplesmente reconhecer funções sintáticas, como sujeito, predicado, objeto direto, etc. Um sintagma simples como o carro de meu irmão de Curitiba permite, de saída, duas formas de estruturação: [o carro [de meu irmão de Curitiba]] ou [[o carro [do meu irmão]] [de Curitiba]]. O que implicam essas duas diferentes segmentações? No primeiro caso, pressupõem que haveria mais de um irmão e o universo discursivo está direcionado a um deles: o que mora em Curitiba. No segundo, inferimos que o irmão em pauta tem mais de um carro em diferentes cidades. Suponhamos que ele trabalha em Curitiba, mas mora em Ponta Grossa e tem um carro em cada cidade - a estrutura faz referência ao carro dele que fica em Curitiba. A ambiguidade, portanto, advém das diferentes possibilidades de estruturação: no primeiro caso, meu irmão de Curitiba especifica carro; no segundo caso, de Curitiba especifica o carro de meu irmão. Geramos, assim, duas estruturas distintas22:

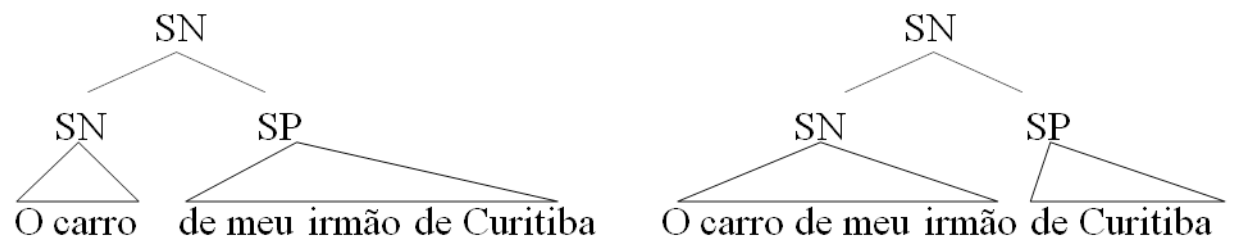

Figura 1: ambiguidade estrutural

Usamos algumas categorias, como sintagma nominal (SN) e sintagma preposicionado $(\mathrm{SP})^{23}$, para mostrar que os elementos que compõem o sintagma nominal "maior" podem se estruturar de duas maneiras diferentes, gerando as duas interpretações. No primeiro caso, o SP é formado pelo constituinte de meu irmão de Curitiba, modificando o carro. No segundo, o SP é de Curiti$b a$, que modifica o sintagma nominal o carro de meu irmão. Desse modo, podemos mostrar que os constituintes obedecem a uma hierarquia e a sua estruturação está ligada à leitura do sintagma maior ou a diferentes leituras, no caso de expressões ambíguas. Num primeiro momento, é secundário identificar o SP com a função de adjunto adnominal, embora esse conhecimento possa ser construído ao longo do tempo. O importante é salientar que, desse modo, a análise sintática toma outra dimensão. Um trabalho nesses moldes ajudará certamente a entender me-

\footnotetext{
22 Dito de outro modo, a ambiguidade advém de duas diferentes possibilidades de estruturação: no primeiro caso, de Curitiba especifica meu irmão; no segundo caso, de Curitiba especifica o carro de meu irmão. Isto é, no primeiro caso, o irmão é de Curitiba, no segundo, o carro é de Curitiba.

23 A gramática tradicional, via de regra, não trabalha com a noção de sintagma e, portanto, não apresenta essa nomenclatura. Para a noção de sintagma, podemos entender que cada categoria gramatical é o elemento central de uma categoria hierarquicamente superior na estrutura da frase, ou seja, a categoria sintagmática. Assim, a categorização dos sintagmas é feita com base nas categorias lexicais (a categoria lexical é o núcleo da categoria sintagmática) (RAPOSO, 1992). Para um trabalho efetivo em sintaxe, não podemos prescindir da noção de sintagma. A esse respeito, ver Kenedy (2010).
} 
lhor as relações de significado, as relações de concordância e dará base para, na escrita, operar com pontuação.

Na próxima seção, vamos aprofundar um pouco mais a forma de se trabalhar com a estruturação de sintagmas e sentenças. Nosso objetivo é mostrar que um trabalho eficiente com a sintaxe da língua traz ganhos efetivos para a compreensão de como a língua se estrutura e isso, consequentemente, colabora com uma maior proficiência tanto na leitura como na escrita.

\section{Refletindo sobre estruturações sintáticas}

O objetivo desta seção é desenvolver a ideia de explicitação de regras gramaticais (sintáticas) como uma atividade de reconhecimento e análise do conhecimento linguístico internalizado. Essa proposta de trabalho se coloca como um primeiro passo para o questionamento e o levantamento de hipóteses acerca do funcionamento da língua (e consequentemente de suas variedades constitutivas).

\section{A gramática na escola/livro didático}

Os manuais e livros didáticos escolares recorrem sempre ao mesmo esquema de apresentação das relações gramaticais existentes em uma frase do português, quando a abordagem da gramática é proposta em sala de aula:

(1) A criança derramou o leite na mesa.

\begin{tabular}{|l|l|}
\hline Sujeito: a criança & Predicado: derramou o leite na mesa \\
Núcleo do suj: criança & AA: o \\
AA: a & Adj. Adv: na mesa \\
VTD: derramou & Prep: em \\
OD: o leite & Núcleo: mesa \\
Núcleo do OD: leite & AA: a \\
& \\
\hline
\end{tabular}

Quadro 1: esquema escolar de análise gramatical

Podemos destacar alguns problemas presentes nessa forma de explicitar a estrutura de uma frase simples como a apresentada em (1) acima. Essa análise não esclarece a disposição hierárquica dos constituintes da frase, pois nela não é possível vislumbrar os elementos menores e sua relação (parte-todo) com os grupos constituintes maiores, nem mesmo ter clareza das relações entre um núcleo e seus circunvizinhos ${ }^{24}$. Além disso, mistura-se categoria gramatical (classe de palavras) com as funções desempenhadas pelos constituintes dentro da oração/período25. Como essa análise não traz uma visão hierárquica consistente, a noção de núcleo não é esclarecida e fica esvaziada. Por meio da metalinguagem tradicional, no entanto, é possível pensar uma representação que, pelo menos, recupere a hierarquia na relação entre os constituintes da sentença:

24 Conforme apresentamos na seção anterior, são diferentes relações hierárquicas que permitem interpretações distintas para a sequência o carro de meu irmão de Curitiba.

25 Maiores detalhes sobre classe e função pode ser encontrado em Perini (1985). 
(2)

\begin{tabular}{|c|c|c|c|c|}
\hline A criança & derramou & o leite & na & mesa \\
\hline \multirow[t]{2}{*}{$\overline{\mathrm{AA}}$} & VTD/N & AA $\mathrm{N}$ & Prep + AA & $\mathrm{N}$ \\
\hline & & OD & Adj. Adv. & \\
\hline Sujeito & & Predicado & & \\
\hline
\end{tabular}

Em (2), visualiza-se uma hierarquia, na medida em que cada traço representa níveis maiores da análise (partindo da palavra para a frase), além de deixar bastante evidente que as sentenças se dividem em dois constituintes principais (sujeito e predicado), que vão se subdividindo até chegar aos elemento menores. No entanto, essa representação, apesar de ser mais eficiente para apresentar as relações hierárquicas, ainda mantém as confusões relativas à classe e à função. Além disso, o núcleo é tratado como se fosse uma categoria do item lexical.

Por conta dessas dificuldades, apresentamos nas próximas subseções algumas saídas, que passam pelos seguintes conjuntos de procedimentos: (a) investir na noção de constituinte e sintagma ${ }^{26}$; (b) utilizar análises em blocos, que são mais intuitivas que as conhecidas árvores sintáticas $^{27}$, para a descrição estrutural das frases (em um segundo momento, pode-se pensar em árvores simplificadas); (c) trabalhar a relações estruturais a partir dos verbos por meio de suas propriedades semânticas e (d) mostrar a estrutura a partir das ambiguidades estruturais; (e) construir perguntas a partir das estruturas.

\section{Trabalhando a estrutura a partir das unidades}

Para levar os alunos à compreensão da estrutura sintática das línguas, uma estratégia é utilizar algo bastante comum nos cursos de introdução à análise sintática, dentro de diferentes perspectivas da linguística. Essas estratégias partem da comparação entre sentenças correlatas, entre paráfrases, que permitem inferir as unidades sintáticas constituintes da frase que estiverem sob análise. ${ }^{28}$

Para exemplificar esse método, consideremos que o aluno tenha o trabalho de localizar o sintagma que desempenha a função de sujeito oracional no enunciado em (3), por meio da comparação com o dado em (4):

(3) O moderno celular da motorola que eu utilizo todos os dias perdeu meus dados.

(4) Ele perdeu meus dados.

26 Esse tipo de análise ganhou corpo como 'análise de constituintes imediatos'. Mais detalhes podem ser encontrados em Raposo (1979).

27 A ideia é mostrar uma reflexão que motiva a representação arbórea.

28 Nas palavras de Negrão, Scher e Viotti (2003): “(...) temos uma intuição a respeito de como as sequências de elementos linguísticos devem se estruturar sucessivamente, de modo a formar unidades mais e mais complexas, até chegarmos à formação de uma sentença. Essas unidades são chamadas de constituintes sintáticos e são os átomos com os quais a sintaxe opera." (p.88, grifo nosso). 
Na comparação das duas sentenças, lado a lado, assume-se que, assim como "ele" é uma unidade indivisível na sintaxe, o que for substituível por este pronome será uma unidade, como segue abaixo:

(5)

\begin{tabular}{|c|l|}
\hline O moderno celular da motorola que eu utilizo todos os dias & perdeu meus dados \\
\hline ele & perdeu meus dados \\
\hline
\end{tabular}

A substituição acima permite inferir a articulação de dois grandes sintagmas da sentença, o que tem sido tradicionalmente chamado de sujeito e predicado. Podemos demonstrar por meio de um teste muito simples uma primeira articulação das frases em português. $\mathrm{O}$ alunos podem, com isso, utilizar sua própria intuição (sua competência gramatical) para fazer os testes e ainda recobrar a consciência de que eles sabem muito sobre sua língua e esse saber pode ser utilizado na construção de um conhecimento explícito sobre a gramática, sobre aquilo que já é parte de sua competência linguística. O que estamos fazendo aqui não é novidade e já foi apontado por Vicente e Pilati (2012) e por Ferreira e Vicente (2015) (além de muitos outros autores que trabalham com testes de constituência). Consideremos agora os seguintes dados:

(6) ${ }^{\star} \mathrm{O}$ moderno ele da motorola que eu utilizo todos os dias perdeu meus dados.

${ }^{*}$ Ele utilizou todos os dias perdeu meus dados.

O aluno pode julgar os casos acima e concluir, tendo em vista as possibilidades de substituição e o julgamento de inaceitabilidade dos dois dados, que a única segmentação possível seja conforme descrito em (5), que recorta os dois grandes sintagmas constituintes das sentenças. Essa divisão é motivada e muito bem aceita em diferentes quadros teóricos de gramática ${ }^{29}$.

A partir desse pequeno caso, é possível trabalhar não só a noção de unidade sintática, a noção de sujeito, como também generalizar esse aspectos para a maioria das sentenças (em ordem direta) do português.

Esse mesmo tipo de teste pode ser útil também para se compreender unidades de diferentes níveis, como vemos nos dados abaixo:

(8) a. O moderno celular da motorola perdeu os meus dados

b. ${ }^{\star} \mathrm{O}$ moderno celular da motorola perdeu os meus eles

c. O moderno celular da motorola perdeu $\underline{\text { eles }}^{\underline{30}}$

29 Nosso parâmetro aqui é a gramática gerativa transformacional, em especial.

30 Como na paráfrase apresentada, é possível usar o português brasileiro em qualquer de suas variedades linguísticas, partindo sempre do que o aluno já traz para sala de aula. Desse ponto, inclusive, se pode estabelecer um contraste entre as diferentes variedades, padrão e não-padrão. Utilizando-se sequências agramaticais, a noção tradicional de erro pode também ser retomada e comparada com o que é possível ou não ocorrer na língua e o que é aceito ou não como norma culta. Retomaremos a importância do trabalho com dados negativos na subseção 2.5 . 
No conjunto de dados acima é possível inferir qual a unidade relativa ao complemento do verbo "perder". Veja que nesse ponto ainda não discutimos nem mesmo as propriedades semânticas específicas dos núcleos lexicais que requisitariam o complemento, mas já é possível uma compreensão preliminar da estrutura.

As próximas subseções seguem no amadurecimento desse tema, pensando na sua função para o ensino de gramática numa perspectiva científica e de descoberta.

\section{Trabalhando a estrutura a partir dos verbos (olhando para as relações com os nú- cleos), por meio de suas propriedades semântico-argumentais.}

Os verbos plenos (em oposição ao verbos auxiliares) são núcleos lexicais importantes e em sua maioria permitem conduzir junto aos alunos uma reflexão intuitiva a respeito de suas propriedades semântico-argumentais. Essa reflexão pode mostrar aos alunos o que é minimamente requerido pelos verbos para construir uma frase no português brasileiro, tomando-se por exemplo verbos como "comprar", "amar", "varrer", “escovar", “temer”. Vejamos um paradigma com o verbo "varrer":
a. O rapaz varreu as calçadas.
b. O rapaz varreu as calçadas na semana passada.
c. ?O rapaz varreu na semana passada.

Do conjunto de dados, é fácil intuir "que falta alguma informação importante" em (9c), a saber as calçadas, e que na semana passada, apesar de contribuir para o conteúdo informacional em (9b), é dispensável em (9a) e não suficiente para preencher a "lacuna" em (9c). Identificam-se aí as primeiras intuições acerca da grade argumental do verbo, seus argumentos, bem como a distinção entre complementos e adjuntos.

Ao se falar em predicado (grosso modo, um núcleo que "faz exigências"), é sempre mais fácil começar com o verbo. A ideia é mostrar, por meio de paradigmas (com dados positivos e negativos), que os argumentos dos verbos (os elementos que satisfazem as exigências do predicador) são mapeados na sintaxe como sujeito (obrigatório) e complemento(s). Já as outras informações, circunstanciais, são mapeadas como adjuntos. Em outros termos, o predicador impõe restrições de dois tipos: 1) sintáticas: a categoria do argumento na sintaxe; e 2) semânticas: propriedades referentes ao "sentido" do argumento na construção. A relação do predicador com seus argumentos pode ser então demonstrada por meio de paradigmas, como o em (10):
a. ${ }^{\star}$ Meu professor comprou _.
b. ${ }^{*}$ _ comprou um carro.
c. Meu professor comprou um carro.

A questão que se coloca, então, é por que a ausência de um dos "participantes" em (10a-b) faz com que não tenhamos uma oração em português, contrariamente a (10c). Ao constatarem que "comprar" obrigada minimamente a presença de dois "participantes" na "cena", os alunos são levados a perceber a atuação dos verbos na formação do esqueleto oracional. Paradigmas como o de (10) podem desdobrar-se em outros: 
(11) a. Meu colega comprou um carro.

b. ${ }^{\star}$ Meu colega comprou por um carro.

c. ${ }^{*}$ Meu colega comprou que João estava na escola.

d. ${ }^{\star}$ Meu colega comprou muito bonito.

(12) a. ${ }^{\star}$ Meu colega percebeu um carro.

b. ${ }^{\star}$ Meu colega percebeu por um carro.

c. Meu colega percebeu que João estava na escola.

d. *Meu colega percebeu muito bonito.

Diante de paradigmas desse tipo, os alunos podem ser levados a questionar por que a expressão "um carro" pode funcionar como complemento (ou como um dos participantes da cena) de "comprar", ao passo que a expressão "que João estava na escola" não pode. Essa mesma expressão, por outro lado, pode ser complemento do verbo "perceber". Outra observação importante tem relação com as imposições categoriais feitas pelos núcleos predicadores. Adicionalmente, os alunos podem ser convidados a construir outros exemplos (positivos e negativos).

\section{Trabalhando a estrutura a partir de sequências ambíguas}

Trabalhar sequências ambíguas, como sinalizado na subseção 1.1, é outra possibilidade de se colocar o conhecimento intuitivo sobre a língua como forma de reconhecer o funcionamento das estruturas gramaticais (sintáticas). Vejamos dois exemplos, dentro do sintagma nominal:

(13) a. O museu de arte do Rio de Janeiro

b. [O museu [de arte [do Rio de Janeiro]]]

c. [[O museu [de arte]] [do Rio de Janeiro]]

(14) a. O filho do diretor que foi preso

b. [O filho [do diretor [que foi preso]]]

c. [[O filho [do diretor]] [que foi preso]]

A sequência em (13a) tem duas interpretações possíveis, que são resultado de dois arranjos sintáticos - duas estruturas hierárquicas distintas. Em uma delas (13b), o sintagma [do Rio de Janeiro] modifica arte, ou seja, está "dentro" do SN [arte], e a interpretação é de que a arte que é do Rio de Janeiro. Em outra (13c), o sintagma [do Rio de Janeiro] modifica museu, pois está "dentro" do SN [museu], gerando a leitura de que o museu que é do Rio de Janeiro. As duas estruturas também podem ser representadas por diagramas arbóreos: 

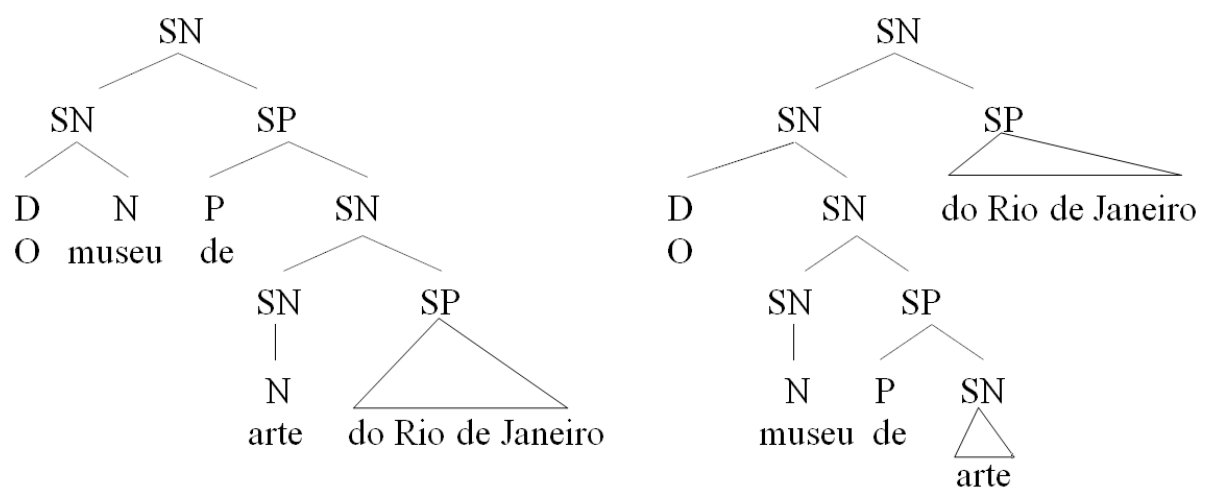

Figura 2: representando a ambiguidade por meio da árvore.

O mesmo trabalho de reconhecimento de ambiguidades pode ser feito para outros exemplos, como (14), instigando os alunos a perceberem a sistematicidade do ponto em questão. Os enunciados em (14) também apresentam duas interpretações possíveis, resultantes de duas possibilidades de estruturação sintática. Numa primeira interpretação, conforme representado em (14b), o diretor foi preso, e a oração subordinada (relativa) "que foi preso" compõe o SN "o diretor"; numa segunda interpretação, o filho do diretor foi preso (isto é, o filho foi preso), conforme representado em (14c); no entanto, em (14c) a subordinada não compõe o SN com "o diretor", mas com "o filho". As duas estruturas descritas acima também podem ser representadas por meio de árvores:
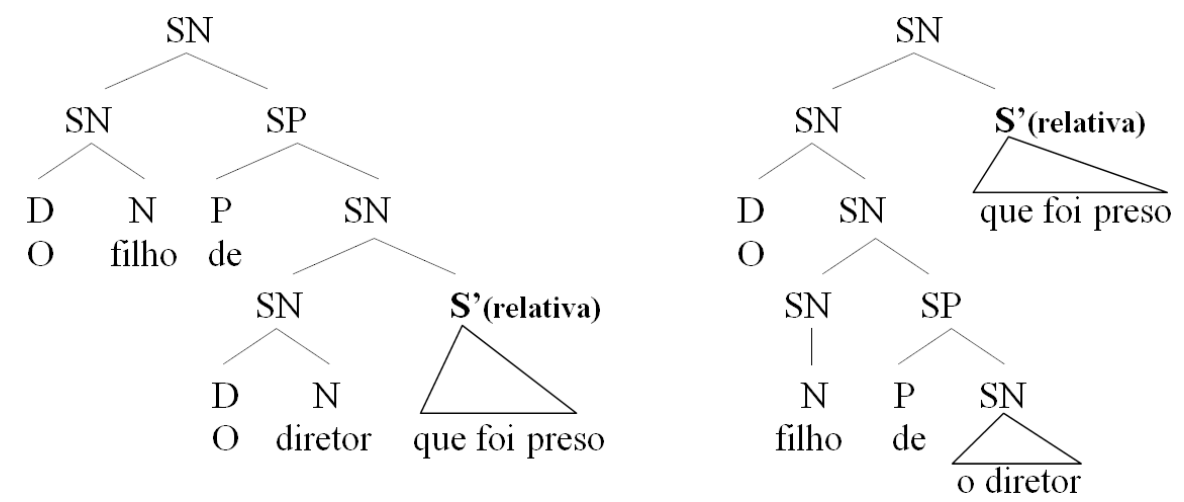

Figura 3: representando a ambiguidade por meio da árvore.

Outro tipo de exemplo muito interessante, que também envolve construções de SN com sintagmas oracionais encaixados, como aparece em (15) abaixo, está relacionado a uma diferença tênue na relação sintática (e semântica) que uma subordinada substantiva e uma subordinada relativa tem com o núcleo do SN. O exemplo abaixo explora as semelhanças e diferenças entre orações substantivas e relativas (adjetivas):

(15) a. [O receio de que o policial atirasse no motorista] perturbou o grupo.

b. O conferencista explicou [o receio de que tanta gente fala].

Embora os SNs entre colchetes, em (15a) e (15b), sejam muito semelhantes, as orações subordinadas presentes neles têm relações diferentes com o elemento subordinador "receio". Em (15a), "receio" toma a oração "o policial atirasse no motorista" como um complemento, como aquilo que impõe medo. Vale registrar que, nesse caso, a oração complemento é regida por meio da 
preposição "de" que é exigida por "receio". Por outro lado, em (15b), o substantivo "receio" toma seu complemento de informações contextuais e a oração "de que tanta gente fala" não é o complemento, mas trata-se, na verdade, de um modificador de "o receio" que o especifica dentre um conjunto de receios a que se poderiam referir os falantes em algum contexto de uso específico. Veja que nesse caso a preposição 'de’ não é exigida por "receio", mas pelo verbo "falar". As representações arbóreas abaixo recuperam exatamente essas propriedades:
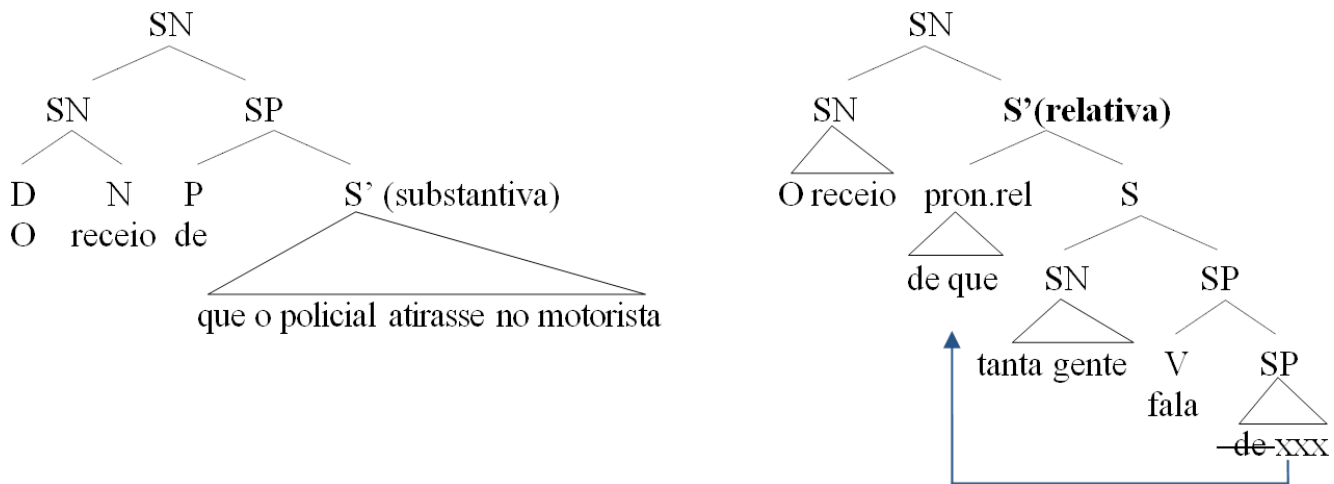

Figura 4: representando a ambiguidade por meio da árvore.

Nas representações acima, observe que a preposição "de" é relacionada a "receio" na árvore da esquerda e a "falar" na árvore da direita (como se vê por meio da seta e da preposição apagada do lado de falar). Vale notar que, apesar das diferentes abordagens desse fenômeno da relativização que existem, a tradição gramatical e muitas gramáticas escolares apresentam a mesma análise apresentada aqui para esses dados ${ }^{31}$.

Apesar de as duas árvores acima já apresentarem alguma complexidade, acreditamos que as intuições exploradas por elas podem ser trabalhadas na escola por meio de outros recursos que recuperem as propriedades sintáticas das relações que uma oração substantiva e uma relativa estabelecem dentro de um sintagma nominal. Além disso, também defendemos que esse conhecimento é muito importante na medida em que é capaz de despertar no aluno intuições mais finas a respeito das relações de dependência de longa distância (como o caso de o verbo falar exigir "de" mesmo sem estar do lado de "de") que revelam propriedades linguísticas importantes e muito exploradas na norma-padrão, principalmente no caso das relativas.

É possível que alguns questionem que os exemplos que usamos em (15) não estão de acordo com os pressupostos que assumimos neste artigo. De fato, esses exemplos pertencem aos registros mais formais do português. Utilizamos esses dados com a intenção de aproximar ao máximo uma subordinada completiva nominal de uma subordinada relativa e também para mostrar os diferentes elos estabelecidos pelas preposições. É possível e desejável, nesses casos, abordar as formas coloquiais das duas subordinadas, que prescindem do uso de preposição.

\footnotetext{
31 Todas as gramáticas tradicionais atribuem a essas subordinadas a análise apresentada na figura 4, embora não usem a representação arbórea. Nenhuma delas, até onde sabemos, compara essas sentenças. Em geral, a classificação de orações subordinadas é feita de maneira estanque. Discute-se a classificação das subordinadas substantivas num momento, e discute-se a configuração das subordinadas adjetivas em outro. Em outras palavras, as subordinadas substantivas são comparadas entre si, nunca com outras subordinadas. A escola e os materiais escolares repetem essa compartimentação.
} 


\section{Encaminhando perguntas a partir das estruturas}

Os questionamentos propostos para trabalho em classe com os alunos não requerem necessariamente respostas imediatas. O desafio é mostrar a sistematicidade da(s) língua(s) e as regularidades gramaticais. A partir disso, somando-se mais exemplos, é possível estabelecer padrões bem como pedir aos alunos que proponham regras explicativas, considerando o funcionamento natural e o uso da língua.

Outra possibilidade é discutir como os dados expostos/trabalhados aparecem no inglês, ou na língua estrangeira usada na escola, ou na Libras dos colegas surdos, ou em alguma língua indígena.

Em outro momento, é possível mostrar que respostas a tradição gramatical tem para os casos; mais adiante, é possível relacionar essas estruturas com a realidade das regras ortográficas e de pontuação vigentes.

Resumindo, pode-se trabalhar a partir de noções como sujeito, complemento e adjunto (partindo-se da noção de argumentos e a obrigatoriedade dos que são mapeados como sujeito ou complemento), bem como com alguma noção de categoria sintagmática (a partir da classe do núcleo). A propósito, o trabalho com uma gramática simplificada como essa já é uma ferramenta bastante eficaz para oferecer uma boa ideia do que seja sistemático na língua.

Nesse ponto, é crucial notar o valor que o dado negativo atribui à análise. Ele é o ingrediente necessário para a percepção de que as regras não são externas, isto é, não vêm do livro/material didático, mas sim são produtos dos saberes dos falantes. Em outros termos, o dado negativo evidencia o que não é possível ocorrer na língua, o que nenhum falante produz ou vai produzir ${ }^{32}$, independentemente do seu grau de instrução. Ainda assim, no paradigma, o dado negativo figura como uma possibilidade combinatória (matemática) que serve como ponto de comparação para o que de fato é passível de ser produzido e processado por um falante.

\section{Considerações Finais}

Neste artigo, buscamos apresentar o que entendemos por gramática como uma ferramenta de descoberta científica, na medida em que fatos - dados positivos e negativos de língua natural são analisados segundo a intuição do falante, tendo-se em mente que os dados da língua estão para os fatos em ciência.

A intuição do falante acerca dos dados é a manifestação da competência (CHOMKSY, 1986) linguística e serve como ferramenta de ensino e aprendizagem dos mecanismos gramaticais (sintáticos) da língua. Tal ensino não se confunde com o ensino da norma culta (tarefa inegável da escola), mas também não exclui a possibilidade de atuar como subsídio para o domínio da modalidade padrão, bem como atuar como subsídio no trabalho com as práticas textuais.

Nesse sentido, revisitamos os conceitos de gramática e apresentamos possibilidades de se explorar a gramática de certos fatos linguísticos, exemplificando com a noção de constituinte e o papel dos verbos na organização da sentença (com foco na sintaxe). Adicionalmente, apresentamos algumas propostas rápidas de encaminhamentos para que os objetivos de ensino de gramática possam ser alcançados.

32 Para efeitos didático-expositivos, desconsideremos dessa afirmação diferenças dialetais e fatores extralinguísticos. 
A forma de se trabalhar a gramática, conforme apresentado nesse artigo, pode se estender ou se complementar por meio da apresentação de exemplos e de informações de outras línguas, de tal modo que se construa uma consciência de que as línguas partilham muitas propriedades, ou seja, não são tão diferentes entre si quanto parecem ser à primeira vista.

\section{Referências}

BACK, Eurico. Fracasso do Ensino de Português: Proposta de Solução. Petrópolis: Vozes, 1987.

BORGES NETO, José Borges. Alguns comentários sobre a iniciação científica na área dos estudos linguísticos. Texto de conferência proferida no X Encontro do CelSul, Cascavel, Unioeste, 28 de outubro de 2012a.

BORGES NETO, José Borges. Algumas observações sobre o ensino de gramática. Texto de conferência proferida no VI ELFE, Maceió, 12 de novembro de 2012b.

CÂMARA JR, Joaquim Mattoso. Estrutura da língua portuguesa. Petrópolis: Vozes, 1970.

CHOMSKY, N. Knowledge of language: its origin and use. New York: Praeger, 1986.

COSTA, João; CABRAL, Assunção Caldeira; SANTIAGO, Ana; VEIGAS, Filomena. Guião de Implementação do Programa de Português do Ensino básico: o Conhecimento Explícito da Língua. Lisboa: Ministério da Educação de, 2011.

FARACO, Carlos Alberto. Norma Brasileira: desatando alguns nós. São Paulo: Parábola, 2008.

FEYNMAN, Richard Phillips. Dever ser brincadeira, Sr. Feynman! Brasília: Editora UNB, 2000.

FERREIRA, E. L. M. e VICENTE, H. G. Linguística gerativa e "ensino" de concordância na Educação Básica: contribuições às aulas de gramática . Linguagem \& Ensino, Pelotas, v.18,n.2, p. 425-455, 2015.

FOLTRAN, Maria José. Ensino de Sintaxe: atando as pontas. In: MARTINS, M. A. (org). Gramática e Ensino. Natal: EdUFRN, 2013.

FRANCHI, Carlos. Criatividade e Gramática. Trabalhos em Linguística Aplicada, v. 9. Campinas, Editora da Unicamp, p.5-45, 1987.

FRANCHI, Carlos. Mas o que é mesmo "Gramática”? In: POSSENTI, S. (org). Mas o que é mesmo "Gramática"? São Paulo: Parábola, 2006.

GERALDI, João Wanderley (org.). O Texto na Sala de Aula: Leitura e Produção. Cascavel-PR: Assoeste Editora Educativa, 1985.

KENEDY, E. Rudimentos para uma nova sintaxe na NGB. Revista do Curso de Letras da UNIABEU Nilópolis, v. I, n.1, Jan- Abr 2010.

LARSON, Richard. Grammar as Science. Cambridge: MIT Press, 2010.

LYONS, John. Introdução à Linguística Teórica. São Paulo: Editora da Universidade de São Paulo, 1979. 
MERCER, José Luiz da Veiga \& FOLTRAN, M. J. Variação Linguística e Ensino de Língua Portuguesa. Revista Letras, 41-42, Curitiba, Editora da UFPR, 1992-93, p. 195-205.

NEGRÃO, Esmeralda Vailati. SCHER, Ana Paula.; VIOTTI, Evani de Carvalho. Sintaxe: explorando a estrutura da sentença. In: Fiorin, J.L. (org). Introdução à Linguística, v. 2. São Paulo: Contexto, 2003.

PÉCORA, Alcir. Problemas de Redação. São Paulo: Martins Fontes, 1983.

PERINI, Mário Alberto. Para uma nova gramática do Português. São Paulo: Ática, 1985.

PERINI, Mário Alberto. Gramática Descritiva do Português Brasileiro. Petrópolis: Vozes, 2016.

PILATI, E et alii. Educação linguística e ensino de gramática na educação básica. Linguagem \& Ensino, Pelotas, v.14, n.2, p. 395-425, jul./dez. 2011.

PIRES de OLIVEIRA, R. e QUAREZEMIN, S. Gramáticas na Escola. Petrópolis: Vozes, 2016.

RAPOSO, Eduardo P. Introdução à gramática generativa: sintaxe do português. Lisboa: Moraes Editora, 1979.

RAPOSO, Eduardo P. Teoria da gramática: a faculdade da linguagem. Lisboa: Caminho, 1992.

VICENTE, H.; PILATI, E. Teoria gerativa e "ensino" de gramática: uma releitura dos parâmetros curriculares nacionais. Verbum - cadernos de pós-graduação, n. 2, p. 4-14, 2012.

VIEIRA, Silvia Rodrigues e BRANDÃO, Silvia Figueiredo. Ensino de gramática: descrição e uso. São Paulo: Contexto, 2016.

Recebido: 06/2017

Aceito: 09/2017 